\title{
Effect of Conjugated Bile Salt Taurodeoxycholic Acid (TDCA) on Mice Colonic Motor Activity
}

\author{
FAIZA ABDU, PhD 1,2 * \\ MAI ALBAIK, PhD ${ }^{2,3}$ \\ ${ }^{1}$ Department of Biological Science, Faculty of Science \\ King Abdulaziz University, Jeddah, Saudi Arabia \\ ${ }^{2}$ Neuroscience Unit, King Fahd Medical Research \\ Center, King Abdulaziz University, Jeddah, Saudi \\ Arabia \\ ${ }^{3}$ Department of Biochemistry, Faculty of Science \\ King Abdulaziz University, Jeddah, Saudi Arabia

\section{*Correspondence:} \\ Prof. Faiza Abdu, P.0. Box 42699, Jeddah 21551, \\ Saudi Arabia \\ E-mail: fabdu@kau.edu.sa.
}

Keywords: TDCA, antagonist, agonist, colon, motility.

Received October 12, 2015

Revised April 13, 2016.

Accepted April 13, 2016.

\begin{abstract}
Background \& Aims: There is an ongoing discussion concerning the role of bile salts on the gastrointestinal motility. Therefore, Taurodeoxycholic acid (TDCA) was studied to investigate the effect of TDCA on mice colonic motility and to examine this mechanism of action in presences histamine antagonist (pyrilamine maleate salt, H1) and serotonin agonist (5-hydroxytryptamine hydrochloride, 5-HT).
\end{abstract}

Methods: Dose response curve of TDCA was performed using different doses of TDCA $(0.3,30,50,100,200,300$ and $500 \mu \mathrm{M})$. Peristaltic motor complexes (PMCs) amplitudes and intervals of contractions were recorded. TDCA inhibitory effect $(300 \mu M)$ on PMCs was studied with presence with $H 1(10 \mu M)$ and 5-HT $(25 \mu M)$.

Results: TDCA inhibits intestine motility through increasing PMC intervals and decreasing PMC amplitudes with doses of 100, 200, 300 and $500 \mu M$ compared to the control values $(P<0.03,0.03,0.01,0.01$ respectively). H1 antagonist $(10 \mu M)$ induced significant reducing in the PMC intervals $(137.2 \pm 13 \mathrm{~S})$ compared to the control values $(255.8 \pm 31 \mathrm{~S}, \mathrm{P}<$ $0.04)$ while there was no response of $5-H T$ agonist $(25 \mu M)$ on interval or amplitude of PMCs regardless applying of TDCA $(300 \mu M)$.

Conclusion: TDCA directly inhibited colon motility may be due to slowing intestinal transit time. These finding is not revealed with presences of histamine antagonist and serotonin agonist.

\section{INTRODUCTION}

R ile salts are surface active compounds; they have physiological funcB tions correlated to their amphipathic molecular structures as digestion and absorption of lipophilic compounds and their detergent nature on protein denaturation (1). Bile salts are also considered as effective signaling molecules in liver and intestine (2).

Bile salts can be synthesized from cholesterol or extracted from the bloodstream by the liver (3). In the liver, bile salts directly modulate their hepatocellular uptake, synthesis and biliary secretion via activation of nuclear receptors and via modulation of cytosolic signaling cascades. They pass from the liver into the small intestine where they reabsorbed from the intestinal lumen to undergo enterohepatic circulation (2).

Bile salts are composed of the salts of bile acids combined with taurine or glycine during many conversions include deconjugation, oxidation and epimerization of hydroxyl groups at $\mathrm{C}_{3}, \mathrm{C}_{7}$ and $\mathrm{C}_{12}$, 7-dehydroxylation, esterification and desulfatation (4). Taurodeoxycholic acid 
(TDCA) is one of bile salts formed by conjugation of deoxycholate with taurine (5).

TDCA inhibits motility, delays gastric emptying and inhibits small bowel transit time (6). This inhibition may due to molecular mechanisms induce gene expression (7) or prostaglandin dependent due to bile acid action on intestinal epithelial cells by elicitation chloride ion secretion (8). Kalia et al. (9) supported the bile-induced secretion resulting from increasing concentrations in the colon.

Gastrointestinal (GI) motility could be influenced by muscarinic and histaminergic modulation (10). Bile acids induce prostaglandin and histamine secretion (8). Histamine is an important cellular messenger of the GI tract while histamine antagonist (pyrilamine maleate salt, $\mathrm{H1}$ ) can stimulate various smooth muscles through activation of $\mathrm{H} 1$ receptors (10).

The secretory actions of TDCA may be partly mediated via a neural pathway through interactions between the intestinal nervous and immune systems (9). Serotonin (5-hydroxytryptamine; 5-HT) has become one of the most investigated and complex biogenic amines (11). Serotonin is found in the enteric nervous system where it is implicated in controlling gastrointestinal motor function (12) through the receptors of serotonin that mediate reflex control of GI motility and secretion (13).

The aim of this study is to investigate the effect of TDCA as a bile salt on mice colonic motility and to examine this mechanism of action in presences of histamine antagonist and serotonin agonist.

\section{MATERIALS AND METHODS}

\section{Experimental Animals}

Experiments were performed on colon segments from Swiss male mice (25-30 g, 4-wk-old). Animals were kept and fed ad libitumin in Animal House of King Fahd Medical Research Centre (KFMRC), Jeddah, Saudi Arabia. The study was approved by the Ethics Committee of KFMRC, King Abdulaziz University.

\section{Chemicals}

Sodium taurodeoxycholate hydrate (Taurodeoxycholic acid, TDCA) and Pyrilamine maleate salt (Histamine antagonist, H1) were purchased from Sigma-Aldrich Corporation (St. Louis, MO USA). 5-Hydroxytryptamine Hydrochloride (Serotonin agonist, 5-HT) was purchased from Spectrum Chemical Manufacturing Corporation (New Brunswick, Gardena, CA).

TDCA was dissolved in dimethylsulphoxide (DMSO, $0.1 \%$ ), while $\mathrm{H} 1$ antagonist and 5-HT agonist were dissolved in distilled water; Solutions were stored at $-20^{\circ} \mathrm{C}$ and then they were freshly diluted and added in microliter volumes to the segment bath during the experiments.

\section{Tissue Preparation}

The experiment was performed according to Abdu et al. $(14,15)$; mice were sacrificed by cervical dislocation, colon segment was rapidly excised and placed in gassed $\left(95 \% \mathrm{O}_{2}\right.$ and $\left.5 \% \mathrm{CO}_{2}\right)$ Krebs bicarbonate buffer solution (composition in mM: $117 \mathrm{NaCl}, 4.7 \mathrm{KCl}, 25 \mathrm{NaHCO}_{3}$, 2.5 $\mathrm{CaCl}_{2}, 1.2 \mathrm{MgCl}_{2}, 2 \mathrm{NaH}_{2} \mathrm{PO}_{4}, 1.2 \mathrm{H}_{2} \mathrm{O}$, and 11 $\mathrm{D}$-glucose), cleared of mesenteric connective tissue, and the lumen was flushed with Krebs solution. Colon segment was prepared and mounted horizontally in separate $20-\mathrm{ml}$ perfusion chambers. The oral and aboral ends of colon segment were secured to two metal catheters fixed at either end of the chamber; the oral end was connected to a perfusion pump for intra-infusion of Krebs solution at a rate of $0.16 \mathrm{ml} / \mathrm{min}$, and the aboral end was attached to a pressure transducer (NeuroLog ${ }^{\mathrm{TM}}$ System, NL900D, Digitimer Ltd., Hertfordshire, UK) to record contractile activity as changes in intraluminal pressure under isovolumetric conditions. Tissues were maintained at $37^{\circ} \mathrm{C}$, perfused with Krebs solution and allowed to equilibrate for at least $10 \mathrm{~min}$ before starting of the experiments. The productivity from the pressure transducers was transmitted to a data-acquisition system (Power1401, Cambridge Electronic Design Ltd., Cambridge, UK) and from there to a computer running Spike 2 version 4 software (Cambridge Electronic Design Ltd., Cambridge, UK), which stored the records for subsequent offline analysis.

\section{Colon Motility}

Peristaltic motor complexes (PMCs) were measured in conditions of their peak amplitude above baseline and were expressed as $\mathrm{cm} / \mathrm{H}_{2} \mathrm{O}$, while period and interval between them were expressed in seconds (S). PMC amplitudes and intervals of contractions were determined 15 min before and after appropriate vehicle.

Dose response curve (DRC) was done for TDCA for the following doses $(0.3,30,50,100,200,300$ and 500 $\mu \mathrm{M}, \mathrm{n}=28,4$ mice for each dose). H1 antagonist and 5-HT agonist were added for $5 \mathrm{~min}$ after stopping perfusion and prior to challenge with TDCA $(300 \mu \mathrm{M}, \mathrm{n}=8$, 4 mice for each chemical), the recording continued for a further $15 \mathrm{~min}$.

TDCA dose $(300 \mu \mathrm{M})$ was selected according to studied DRC. Dose of $\mathrm{H} 1$ antagonist $(10 \mu \mathrm{M})$ was chosen according to Abdu et al. study done in (15) while 5-HT agonist $(25 \mu \mathrm{M})$ dose was obtained according to Michel and Kendall study (16).

\section{Statistical analysis}

Responses are expressed as absolute values \pm SE. Data compared using "student's" $t$-test paired or unequal variances as appropriate. Probability of $P<0.05$ was considered as significant. 


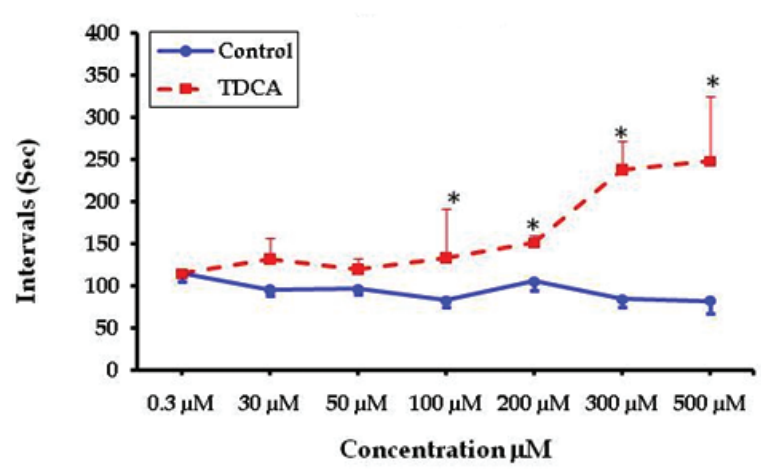

Figure 1. Effect of TDCA on PMC intervals

Effect of different doses $(0.3,30,50,100,200,300$ and $500 \mathrm{mM})$ of TDCA on the PMC intervals. Values represents mean $\pm S E$ of 4 colon segments from different animals. $(P<0.05)$ Significantly different compared to the control group.

\section{RESULTS}

\section{Dose response curve of TDCA}

The contractile activity of luminal distension of isolated colon segment expressed physiologically by continuous peaks (amplitudes) separated by relaxation (intervals). The dose response effect of TDCA, a bile salt, on the colonic PMCs was done using different doses $(0.3$, $30,50,100,200,300$ and $500 \mu \mathrm{M}, \mathrm{n}=28,4$ mice for each dose).

TDCA significantly amplified the values of the PMC intervals (Fig. 1) in a dose response manner after treatment of the colon with the $100,200,300$ and $500 \mu \mathrm{M}$ doses compared to the control values $(P<0.03,0.03$, $0.01,0.01$ respectively).

In the meantime, treatment of the mice colon segments with TDCA doses caused significant dose response drop in the amplitudes of the PMCs at the 100, 200,300 and $500 \mu \mathrm{M}$ doses in comparison with the untreated colon segments $(P<0.02,0.03,0.01,0.05$ respectively, Fig. 2).

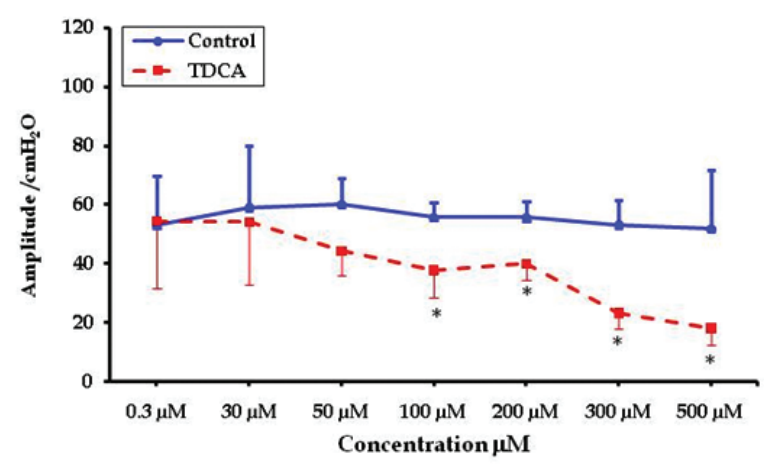

Figure 2. Effect of TDCA on PMC amplitudes Effect of different doses (0.3, 30, 50, 100, 200, 300 and $500 \mathrm{mM})$ of TDCA on the PMC amplitudes. Values represents mean $\pm S E$ of 4 colon segments from different animals. $(P<0.05)$ Significantly different compared to the control group.

\section{Effect of TDCA in the presence of Histamine antagonists on PMCs}

There was no effect for TDCA treatment $(300 \mu \mathrm{M})$ after incubation of histamine antagonist $(\mathrm{H} 1,10 \mu \mathrm{M})$ on interval or amplitude of PMCs of mice colon, Fig. 3. Moreover, $\mathrm{H} 1$ antagonist $(10 \mu \mathrm{M})$ induced significant reducing in the PMC intervals $(137.2 \pm 13$ S) compared to the control values $(255.8 \pm 31 \mathrm{~S}, P<0.04)$, Fig. 5 .

\section{Effect of TDCA in the presence of Serotonin agonists on PMCs}

The response of serotonin (5-HT, $25 \mu \mathrm{M})$ as agonist for bile salt TDCA on colonic motility is illustrated in Fig. 4 and 6. There was no response of 5-HT agonist (25 $\mu \mathrm{M})$ on interval or amplitude of PMCs regardless applying of TDCA $(300 \mu \mathrm{M})$.

\section{Discussion}

The study findings indicate that TDCA inhibits intestine motility through increasing PMC intervals and decreasing PMC amplitudes. This finding is demonstrated
Figure 3. Effect of TDCA in the presence of histamine antagonist on colon motility

Representative recording traces showing the effect of TDCA (300 $\mu M)$ in the presence of histamine antagonist $(\mathrm{H1}, 10 \mathrm{mM})$ on colon motility.

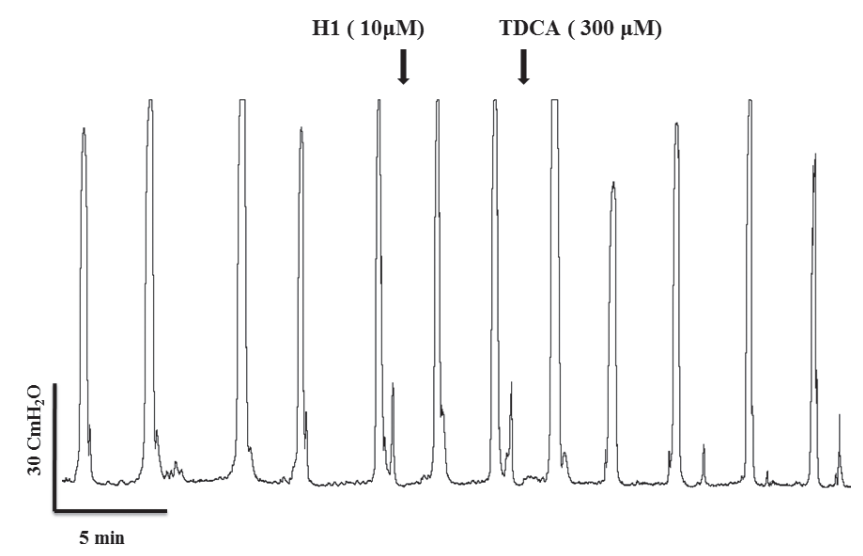




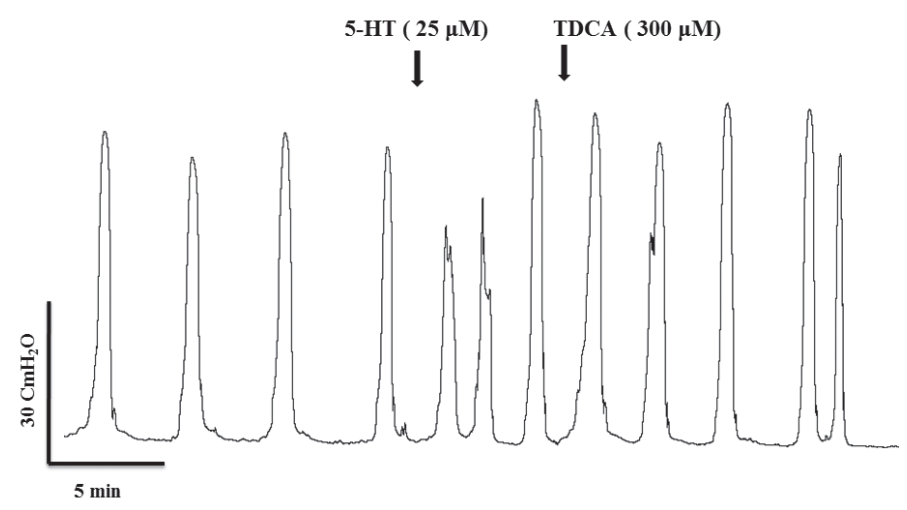

with previous studies $(6,8)$ while it is inconsistent with $(9,17)$. Kalia et al. (9) reported that TDCA increases the motility through amplification of intestinal secretion, activation of mast cells and other inflammatory cells, while Poole et al. (17) suggested the inability of TDCA to inhibit contractile activity of the isolated ileum due to the hydrophilic property of TDCA which does not effectively access target neurons within the small intestine.

The ability of TDCA to inhibit motility can be explained by Mühlbauer et al. (7) who suggested molecular mechanisms underlying the bile acid-induced gene expression; TDCA induced IL-8 expression in a dose and time-dependent manner. Martínez-Augustin and his col-
Figure 4. Effect of TDCA in the presence of serotonin agonist on colon motility

Representative recording traces showing the effect of TDCA $(300 \mu M)$ in the presence of serotonin agonist $(5-H T, 25 \mathrm{mM})$ on colon motility
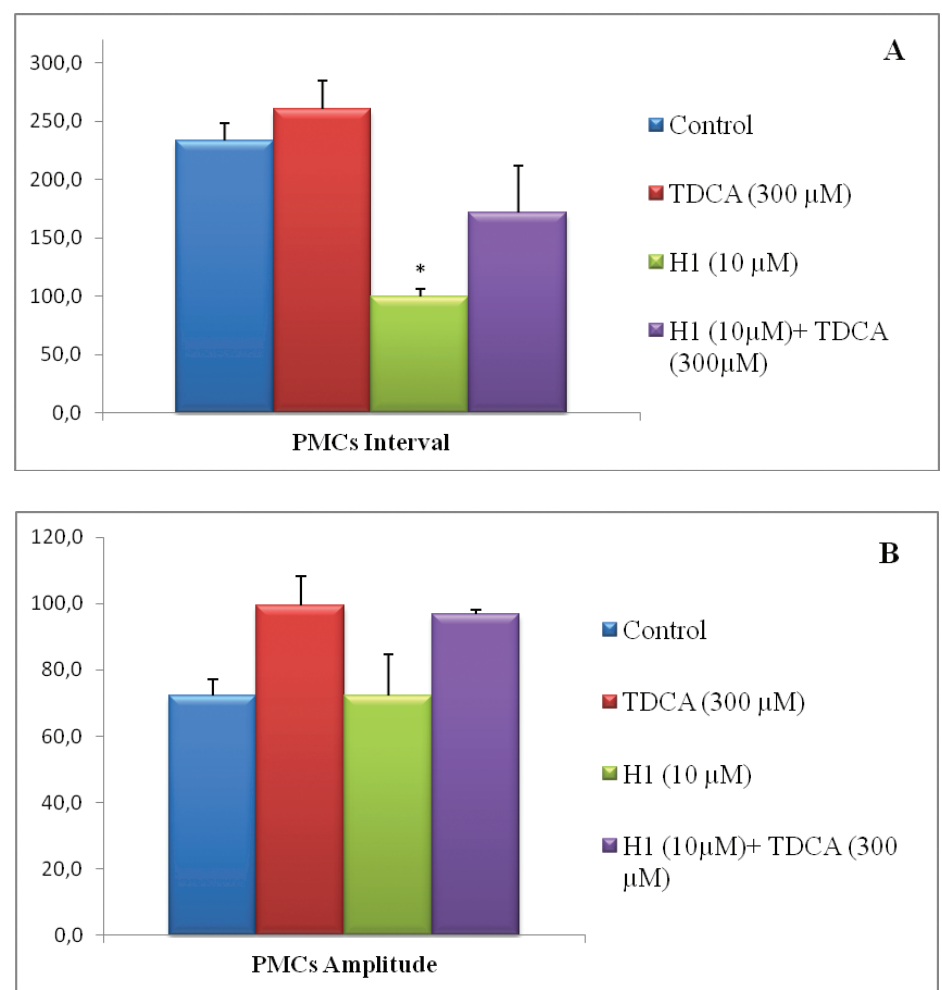

Figure 5. Effect of TDCA in the presence of histamine antagonist on interval $(A)$ and amplitude $(B)$ of PMCs

Effect of TDCA $(300 \mu M)$ in the presence of H1 antagonist $(10 \mathrm{mM})$ on PMCs intervals $(A)$ and amplitudes (B)ofmice colon. Values represents mean $\pm S E$ of 4 colon segments from different animals. *Significantly different compared to the control group, $(P<0.05)$. 

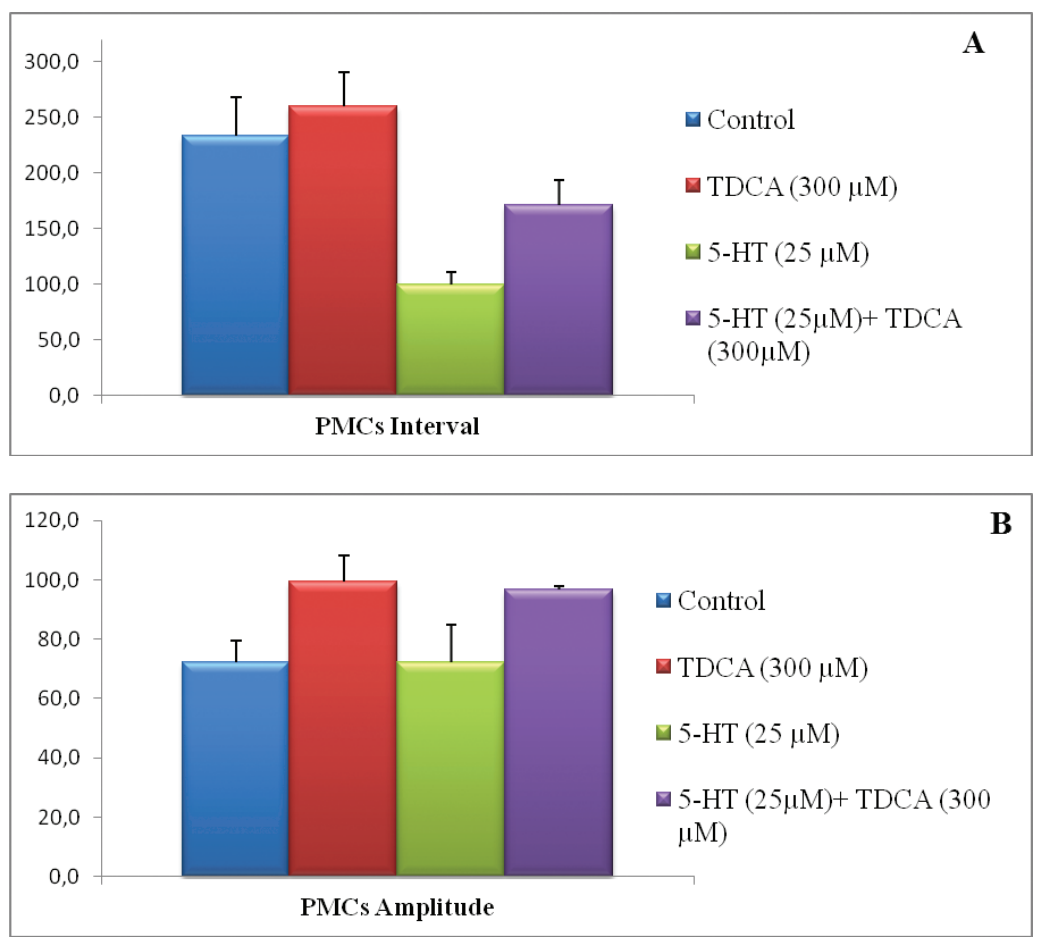

Figure 6. Effect of TDCA in the presence of serotonin agonist on interval $(A)$ and amplitude $(B)$ of PMCs

Effect of TDCA $(300 \mu M)$ in the presence of 5-HT agonist $(25 \mathrm{mM})$ on PMCs intervals (A) and amplitudes (B) of mice colon. Values represents mean $\pm S E$ of 4 colon segments from different animals.

Psychological stress plays a major role in functional gastrointestinal disorders, it induced activation or sensitization of mucosal mast cells in the GI tract seem to be involved in stress-associated alterations of visceral sensitivity (20). Psychological stress accelerated reverse cholesterol transport (RCT) by compromising intestinal cholesterol absorption (21) confirming the increase in releasing of TDCA to inhibit the intestinal motility.

Results from this study confirmed that histamine antagonist $(10 \mu \mathrm{M})$ induced significant reducing in the PMC intervals compared to the control. Earlier studies suggested that antagonists mediate by inhibition of cholinergic neurotransmission through a pertussis toxin sensitive mechanism (6); Histamine antagonist, can block the uptake of monoamines in the central nervous system (22), block central muscarinic receptors (23) and block H1 receptors-mediated channels (10). On other side, pyrilamine enhances dopaminergic activity through $\mathrm{H} 1$ receptor blockade at the level of dopamine (22). Cholinomimetic mechanisms are also involved in the regulation of excitatory action of GI smooth muscles (10).

Although autonomic modulation of GI function occurs via the actions of neurotransmitters and neuromodulators such as serotonin (24) through mediating the receptors of serotonin of motility and secretion, our results showed no response of serotonin agonist $(25 \mu \mathrm{M})$ on motor activity with or without TDCA applying $(300 \mu \mathrm{M})$ which is disagreed with previous study $(12,13,25)$. This discrepancy is explained by small dose of applied serotonin $(25 \mu \mathrm{M})$ since Sasaki-Adams and Kelley (26) suggested that chronically increased levels of 5-HT may facilitate modulatory mechanisms.

In conclusion, this study has shown that TDCA directly inhibited terminal colon motility. It is possible that this effect on colon motor activity exposed by slowing intestinal transit time. These finding is not revealed with low concentration of histamine antagonist and serotonin agonist

Acknowledgements: This project was funded by the Deanship of Scientific Research (DSR), King Abdulaziz University, Jeddah, grant no. (515/247/1431). The authors, therefore, acknowledge with thank DSR technical and financial support.

\section{REFERENCES}

1. HOLM R, MÜLLERTZ A, MU H 2013 Bile Salts and their Importance for Drug Absorption. Int. J. Pharm. 453: 44- 55 http:// dx.doi.org/10.1016/j.ijpharm.2013.04.003

2. MAILLETTE DE BUY WENNIGER L, BEUERS U 2010 Bile Salts and Cholestasis. Dig. Liver Dis. 42:409-418 http://dx.doi. org/10.1016/j.dld.2010.03.015 
3. SENEFF S, WAINWRIGHT G, MASCITELLI L 2011 Is the Metabolic Syndrome Caused By a High Fructose, and Relatively Low Fat, Low Cholesterol Diet? Arch. Med. Sci. 7(10): 8-20 http:// dx.doi.org/10.5114/aoms.2011.20598

4. GÉRARD P 2014 Metabolism of Cholesterol and Bile Acids by the Gut Microbiota. Pathogens 3: 14-24 http://dx.doi.org/10.3390/ pathogens3010014

5. IJARE OB, SOMASHEKAR BS, JADEGOUD Y, NAGANA GOWDA GA $2005{ }^{1} \mathrm{H}$ and ${ }^{13} \mathrm{C}$ NMR Characterization of Bile Acids. Lipids 40: 1031-1041 http://dx.doi.org/10.1007/s11745005-1466-1

6. ARMSTRONG DN, KRENZ HK, MODLIN IM, BALLANTYNE GH 1993 Bile Salt Inhibition of Motility in the Isolated Perfused Rabbit Terminal Ileum. Gut 34: 483-488 http://dx.doi. org/10.1136/gut.34.4.483

7. MÜHLBAUER M, ALLARD B, BOSSERHOFF AK, KIESSLING S, HERFARTH H, ROGLER G, SCHO"LMERICH J, JOBIN C, HELLERBRAND C 2004 Differential Effects Of Deoxycholic Acid and Taurodeoxycholic Acid on $\mathrm{NF}_{-} \mathrm{B}$ Signal Transduction and IL-8 Gene Expression in Colonic Epithelial Cells. Am. J. Physiol. Gastrointest. Liver Physiol. 286: G1000G1008 http://dx.doi.org/10.1152/ajpgi.00338.2003

8. MARTÍNEZ-AUGUSTIN O, SÁNCHEZ DE MEDINA F 2008 Intestinal Bile Acid Physiology and Pathophysiology. World J. Gastroenterol. 14(37): 5630-5640 http://dx.doi.org/10.3748/ wjg. 14.5630

9. KALIA N, HARDCASTLE J, KEATING C, GRASA L, KEATING C, PELEGRIN P, BARDHAN KD, GRUNDY D. 2008 Intestinal Secretory And Absorptive Function in Trichinella Spiralis Mouse Model of Postinfective Gut Dysfunction: Role of Bile Acids. Gut 57(1): 41-49 http://dx.doi.org/10.1136/gut.2006.118356

10. HUANG W, HUANG X, XING Z, QIU X, WANG Y, FAN R, LIU W, REN P, LIU Z, ZHOU H 2011 Meranzin Hydrate Induces Similar Effect to Fructus Aurantii on Intestinal Motility through Activation of H1 Histamine Receptors. J. Gastrointest. Surg. 15: 87-96 http://dx.doi.org/10.1007/s11605-010-1374-9

11. PITHADIA AB, JAINA SM 2009 5-Hydroxytryptamine Receptor Subtypes and their Modulators with Therapeutic Potentials. Clin. Med. Res. and Elmer. Press 1(2): 72-80 http://dx.doi. org/10.4021/jocmr2009.05.1237

12. TALLEY NJ 1993 Review Article: 5-Hydroxytryptamine Agonists and Antagonists in the Modulation of Gastrointestinal Motility and Sensation: Clinical Implications. Aliment Pharmacol Ther. 6(3): 273-289 http://dx.doi.org/10.1111/j.1365-2036.1992. tb00050.x

13. CROWELL MD 2001 The Role of Serotonin in the Pathophysiology of Irritable Bowel Syndrome. Am. J. Manag. Care 7(8 Suppl): S252-60

14. ABDU F, HICKS GA, HENNIG G, ALLEN JP, GRUNDY D 2002 Somatostatin sst(2) Receptors Inhibit Peristalsis in the Rat and Mouse Jejunum. Am. J. Physiol. Gastrointest. Liver. Physiol. 282(4): G624-633 http://dx.doi.org/10.1152/ajpgi.00354.2001
15. ABDU F, ALMUHAMMADI A, ALAMRI J, OMRAN MA, BADAWOUD MH 2014 Effect of Cholic Acid on Colonic Motility in Mice. Afr. J. Pharm. Pharmacol. 7(26): 1825-1833 http:// dx.doi.org/10.5897/AJPP2013.3443

16. MICHEL CC, KENDALL S 1997 Differing Effects of Histamine and Serotonin on Microvascular Permeability in Anaesthetized Rats. Journal of Physiology 501(3): 657-662 http://dx.doi. org/10.1111/j.1469-7793.1997.657bm.x

17. POOLE DP, GODFREY C, CATTARUZZA F, COTTRELL GS, KIRKLAND JG, PELAYO JC, BUNNETT, NW, CORVERA, CU 2010 Expression and Function of the Bile Acid Receptor GPBAR1 (TGR5) in the Murine Enteric Nervous System. Neurogastroenterol. and motil. 22(7): 814-e228 http://dx.doi. org/10.1111/j.1365-2982.2010.01487.x

18. KEATING N, KEELY SJ 2009 Bile Acids in Regulation of Intestinal Physiology. Curr. Gastroenterol. Rep. 11:375-382 http:// dx.doi.org/10.1007/s11894-009-0057-8

19. DINU C, DIACONESCU C, AVRAM N, CUCĂ D 2009 Changes in the Bile-Acids Composition of Bile Juice after Fat Intake. Zootehnie şi Biotehnologii 42(1): 230-234

20. MÖNNIKES H, TEBBE JJ, HILDEBRANDT M, ARCK P, OSMANOGLOU E, ROSE M, KLAPP B, WIEDENMANN B, HEYMANN-MÖNNIKES I 2001 Role of Stress in Functional Gastrointestinal Disorders. Evidence for Stress-Induced Alterations in Gastrointestinal Motility and Sensitivity. Dig Dis. 19(3): 201-211 http://dx.doi.org/10.1159/000050681

21. SILVENNOINEN R, ESCOLA-GIL JC, JULVE J, ROTLLAN N, LLAVERIAS G, METSO J, VALLEDOR AF, HE J, YU L, JAUHIAINEN M, BLANCO-VACA F, KOVANEN PT, LEERUECKERT M 2012 Acute Psychological Stress Accelerates Reverse Cholesterol Transport via Corticosterone-Dependent Inhibition of Intestinal Cholesterol Absorption. Circ Res. 111(11):1459-1469 http://dx.doi.org/10.1161/CIRCRESAHA.112.277962

22. LOZEVA V, VALJAKKA A, LECKLIN A, OLKKONEN H, HIPPELÄINEN M, ITKONEN M, PLUMED C, TUOMISTO L. 2000 Effects of the Histamine H(1) Receptor Blocker, Pyrilamine, on Spontaneous Locomotor Activity of Rats With LongTerm Portacaval Anastomosis. Hepatology 31: 336-344 http:// dx.doi.org/10.1002/hep.510310212

23. DE RUITER J 2001 Histamine H1-Receptor Antagonists: Antihistaminic Agents. Principles of Drug Action 2: 1-20

24. GERSHON MD 2004 Serotonin and Its Implication for the Management of Irritable Bowel Syndrome. Rev. Gastroenterol. Disord. 3 Suppl 2: S25-34

25. HABERZETTL R, FINK H, BERT B 2015 The Murine Serotonin Syndrome - Evaluation of Responses to 5-HT-Enhancing Drugs in NMRI Mice. Behav. Brain Res. 277: 204-210 http://dx.doi org/10.1016/j.bbr.2014.04.033

26. SASAKI-ADAMS DM, KELLEY AE 2001 Serotonin-Dopamine Interactions in the Control of Conditioned Reinforcement and Motor Behavior. Neuropsychopharmacology 25: 440-452 http:// dx.doi.org/10.1016/S0893-133X(01)00240-8 